\title{
Behçet Uveitis in the American Midwest
}

Omar A Saleh, MD르, Andrea D Birnbaum, MD, PhD², Howard H Tessler, MD¹, Debra A Goldstein, MD 1

Keywords: Behçet disease; vasculitis; uveitis; hypopyon; HLA-B51

1. University of Illinois at Chicago

Department of Ophthalmology and Visual Science, Chicago, Illinois

2. Northwestern University, Feinberg School of Medicine

Department of Ophthalmology, Chicago, Illinois

Corresponding author:

Debra A Goldstein, MD

Professor

University of Illinois at Chicago

Department of Ophthalmology and Visual Sciences

1855 West Taylor Street

Chicago, IL 60612

312-996-6660 (phone), 312-355-0520 (fax)

debrgold@uic.edu 


\begin{abstract}
Purpose: Behçet disease is most common in Asia, the Middle East and North Africa (Silk Road). We compare clinical presentation and course of Behçet uveitis in patients of Silk Road and non-Silk Road descent.

Methods: Retrospective review of patients evaluated at the University of Illinois January 1983 - July 2010.

Results: Of 6134 new uveitis patients, 36 with available medical records met diagnostic criteria for Behçet disease. 10 (28\%) were of Silk Road origin.

Retinal vasculitis was the most common ocular manifestation, followed by panuveitis and retinitis. Ocular and systemic manifestations were similar between groups. 78\% were treated with systemic immunosuppression, which reduced inflammatory attack rate. Conclusions: Behçet disease is uncommon in the Midwest United States. Three quarters of patients in this series were not of Silk Road descent. Physicians should consider the diagnosis of Behçet disease in any patient with retinal vasculitis or uveitis regardless of ethnicity.
\end{abstract}




\section{Introduction}

Behçet disease is a multi-system inflammatory disease named after the Turkish dermatologist, Hulusi Behçet, who described a triad of recurrent oral ulcers, genital ulcers, and iritis in $1937^{1}$. Characterized pathologically by a necrotizing occlusive vasculitis of arteries or veins, the disease may affect any organ system and may therefore give rise to a wide spectrum of clinical features ${ }^{2}$. The usual course of the disease is that of recurrent inflammatory episodes.

Behçet disease occurs worldwide. However, the prevalence of Behçet disease varies considerably between different geographic and racial distributions. The highest prevalence occurs in countries of the "Silk Road", which refers to a network of interconnected silk trade routes that ran from China to the Mediterranean for thousands of years. It connected many countries from East, South, and Western Asia with the Mediterranean world including North Africa and South Europe ${ }^{3}$. In fact, Behçet disease has been given the name "Silk Road Disease"4. Because of this, much of the data on the ocular manifestations of Behçet disease comes from Turkey and Japan.

The diagnosis of Behçet disease is based on the finding of specific clinical symptoms and signs, as there is no specific laboratory test. Several sets of diagnostic criteria have been described. The Behçet Disease Research Committee of Japan devised a set of criteria for the diagnosis of Behçet disease in 19745, and the International Study Group (ISG) for Behçet disease published diagnostic criteria in $1990^{6}$. According to ISG criteria, the 
diagnosis of Behçet disease requires the presence of recurrent oral ulceration in addition to at least two other features: recurrent genital ulceration, typical eye lesions, typical skin lesions, or positive pathergy test.

Although neurological and major vessels disease may lead to life-threatening complications, their involvement in Behçet disease remains rare ${ }^{7}$. Ocular involvement in Behçet disease has been reported in up to $50 \%$ of patients ${ }^{8}$. The exact etiopathogenesis of Behçet disease is still unclear, but it is generally believed to represent an enhanced or dysregulated immune response triggered by environmental factors in immunogenetically susceptible individuals 9 .

We describe the presentation, ocular and systemic features, and response to treatment of patients with Behçet uveitis seen in a single center in the Midwest United States. Patients of Silk Road descent (Asian including Asian Indian, White-Middle Eastern, and White-North African) are compared with patients of non-Silk Road descent (WhiteEuropean, Hispanic, and African American) evaluated at the same center. 


\section{Materials and Methods}

We were granted permission from the institutional review board at the University of Illinois at Chicago to retrospectively review existing medical records of patients evaluated by the uveitis service between January 1983 and July 2010 with a diagnosis of Behçet disease. Only patients with available medical records who met the ISG criteria for the diagnosis of Behçet disease were included in the data analysis. In order for uniformity of diagnosis, patients who met only Behçet Disease Research Committee of Japan criteria were excluded.

Demographic information was collected based on self-reported data obtained via a questionnaire administered to each patient at the time of presentation to the uveitis service, including race, ethnicity, and country of origin. For purposes of comparison, patients were divided into two groups based on their race/ethnicity and country of origin: patients of Silk Road origin (SR) included those originating from East Asia, Indian subcontinent, Middle East, and North Africa, and patients not of Silk Road origin (NSR) including those originating from Europe, Africa, and the Americas. Throughout the period of follow up, examination findings were recorded including visual acuity, ocular examination, and ancillary testing. When available, results of optical coherence tomography (OCT), fundus fluorescein angiography (FA), and visual field tests were reviewed.

Best corrected Snellen visual acuity (BCVA) values were converted to logarithm of minimum angle of resolution equivalent units ( $\log M A R)$ for the purposes of statistical calculations. LogMAR equivalent values for "counting fingers at 2 feet" and "hand motion at 
2 feet" acuities were classified as +2 and +3 , respectively. Eyes with light perception or no light perception vision and uninvolved eyes in unilateral cases were not included in visual acuity calculations. Improvement or worsening of BCVA was interpreted when a decrease or an increase of more than $0.2 \log$ MAR units was documented, respectively. Poor vision was defined as BCVA of 20/200 or worse in at least one eye.

Classification of uveitis, as well as grading of anterior and posterior segment inflammation, was determined using the Standardization of Uveitis Nomenclature (SUN) criteria $^{10}$. Retinal vasculitis was diagnosed when leakage of retinal vasculature was detected on FA and/or when perivascular infiltration or vascular sheathing was clinically visible. Epiretinal membranes and cystoid macular edema were detected clinically and/or by FA or OCT. Intraocular pressure (IOP) measured by Goldmann Tonometer at the first visit was considered a patient's baseline IOP. Glaucoma was diagnosed if characteristic optic nerve or visual field abnormalities were documented.

Medications received for the treatment of uveitis were documented. In patients who received chlorambucil or biologic agents, the response to these agents was evaluated after reporting the number of uveitis attacks per year during at least 12 months before and 12 month after starting therapy.

Statistical analysis

Two-tailed Fisher exact test was used for the differences in frequencies between the two subgroups and Wilcoxon matched-pairs signed-rank test was used for the response of patients to therapy. A $p$-value of $<0.05$ was considered statistically significant. 


\section{Results}

A total of 6134 new uveitis patients were evaluated at the uveitis service at the University of Illinois at Chicago (UIC) between January 1983 and July 2010. Of these, 101 patients had been classified as having Behçet disease. After review of available medical records, 36 patients met the ISG criteria and were included in the study. The remaining patients either met only the Behçet Disease Research Committee of Japan criteria, or had incomplete medical records.

Twenty six patients (72\%) were of NSR origin: 18 were White-European, 5 were African American, and 3 were Hispanic; 10 patients (28\%) had SR origins (6 Asian including 3 Chinese, 2 Asian Indian, and 1 Korean, and 2 White-Middle Eastern from Saudi Arabia, and 2 North African including 1 Egyptian and 1 Moroccan). During this same time period, only $5.3 \%$ of the new patients seen by the uveitis service were of SR ancestry $(\mathrm{p}<0.01)$

Of all patients, $22(61 \%)$ were male (54\% of NSR and $80 \%$ of SR patients) with no statistically significant difference between subgroups. Average age at presentation was 34 years (10-53 years). Thirty two patients (89\%) had bilateral disease at any time during the course of the disease. Twenty six patients underwent testing for HLA-B51 serotype; 15 (58\%) were positive with no significant difference between NSR and SR patients $(\mathrm{P}>0.99)$. The most common ocular manifestations were retinal vasculitis associated with anterior uveitis followed by panuveitis. Ocular features at presentation are shown in Table 1.

Thirty five patients (97\%) were diagnosed with Behçet disease as part of their uveitis evaluation; only 1 patient carried the diagnosis at presentation. At initial presentation to the uveitis service, 27 (75\%) patients reported systemic features of Behçet 
disease which preceded their eye manifestations by an average of 2.5 years. Six patients (17\%) manifested systemic and eye features at approximately the same time, and only 3 (8\%) patients had only uveitis as their onset manifestation of Behçet disease and developed systemic features at a later date. There was no significant difference in the pattern of presentation between SR and NSR patients.

Twenty nine (81\%) patients (73\% of NSR and $100 \%$ of SR patients) did not meet the diagnostic criteria for Behçet disease prior to development of uveitis. In 6 patients (17\%), all from the NSR group, the criteria were met but the diagnosis was not made until after presentation to the uveitis service. The systemic manifestations of Behçet disease in both groups of patients are summarized in Table 2 .

Ocular complications are shown in Table 3. All complications were similar between groups, with the exception of epiretinal membrane (ERM), which was more common in SR patients $(\mathrm{p}=0.02)$.

Thirteen patients (36\%) presented with BCVA of $\leq 20 / 200$ in at least one eye. Nine were male and 9 were of NSR descent. Three patients (8\%) presented with BCVA of $\leq 20 / 200$ in their better seeing eye. There was no significant association between ethnicity $(\mathrm{P}>0.99)$, gender $(\mathrm{P}=0.50)$, or HLA B5genotype $(\mathrm{P}>0.99)$ and poor vision at presentation. The majority of patients received corticosteroids in various forms (89\% of patients received topical, $83 \%$ systemic, and $36 \%$ periocular). Seventy-eight percent ( $\mathrm{n}=28$ patients) received systemic immunosuppression therapies, most frequently chlorambucil $(39 \%, n=14)$, cyclosporine $(25 \%, n=9)$, methotrexate $(19 \%, n=7)$, and tumor necrosis factor (TNF) inhibitors (14\%, n=5). Half of the patients evaluated between 1985 and 2005 who required immunosuppression received chlorambucil $(n=14)$. None received TNF 
inhibitors. After 2005, 18\% of those patients requiring immunosuppression received TNF inhibitors $(\mathrm{n}=5)$ and $29 \%$ received chlorambucil $(\mathrm{n}=8)$.

The response to therapy with chlorambucil was evaluated in patients who had been followed for at least 12 months prior to and at least an additional 12 months after initiation of therapy. Eighteen eyes of 9 patients fit these criteria. Median duration of follow-up after starting chlorambucil therapy was 23 months (range 12 to 73 months). The regimen used has been previously described and consisted of an incrementally increasing high-dose short-term chlorambucil protocol ${ }^{11}$. The mean duration of chlorambucil therapy was only 4.8 months (range 3 to 11 months). None of the patients were still on therapy a year after initiation. The number of attacks of ocular inflammation per year was documented before starting therapy and compared to the number of attacks per year after starting therapy. The median number of attacks per year was significantly reduced with chlorambucil therapy from 2.5 prior to therapy to 0.8 after starting therapy (Positive Wilcoxon value $(+W)=45$, negative Wilcoxon value $(-W)=0, N=9, p<=0.004)$. One year after chlorambucil therapy was started; BCVA improved in 12 eyes (67\%), was stable in 4 eyes (18\%), and decreased in 2 eyes (11\%). Overall, the median BCVA improved from 20/71 just before starting therapy to 20/36 a year after starting therapy, and the median BCVA logMAR equivalent decreased from 0.55 to $0.25(+\mathrm{W}=98.50,-\mathrm{W}=21.50, \mathrm{~N}=15, \mathrm{p}<=0.026)$. Transient nausea and arm paresthesia were the only reported adverse effects. Statistically, there was no significant difference in the clinical response to therapy between NSR and SR patients.

Five patients (10 eyes) received biologic agents for the treatment of Behçet uveitis, with follow up for at least 12 months prior to and after starting therapy with a median 
post-therapy follow-up of 22 months (range 12 to 36 months). The average duration of therapy with biologic agents was 17.8 months \pm 6 months (see Table 4).

The median number of attacks of ocular inflammation per year was reduced from 2 prior to biologic therapy to 0 after starting therapy $(+W=15,-W=0, N=5, p<=0.063)$. Two of the patients were still on biologic therapy at the time of data collection. BCVA improved in 6 eyes (60\%) and remained stable in 4 (40\%). Overall, the median BCVA improved from 20/40 just before therapy to 20/20 a year after therapy and the median BCVA logMAR equivalent changed from 0.3 before onset of therapy to zero a year after therapy $(+W=36$, $\mathrm{W}=0, \mathrm{~N}=8, \mathrm{p}<=0.008$ ). Adverse effects were reported in only one patient who experienced 5 upper respiratory infections in the first 6 months of adalimumab therapy, and no further infections after switching to infliximab. 


\section{Discussion}

Behçet disease is an uncommon cause of uveitis in the American Midwest, as evidenced in this study by the low number of patients with Behçet uveitis seen at a large tertiary referral center. Although the majority of these patients were of NSR ancestry, the proportion of patients of SR ancestry was significantly higher than would be expected when compared to all uveitis patients evaluated at the same institution during the same time period. This is consistent with reported data regarding the prevalence of Behçet disease, with the highest prevalence in Turkey and a low rate in the United States of America ${ }^{12,8}$.

Although no pathognomonic test exists for the diagnosis of Behçet disease ${ }^{12}$, the disease is strongly associated with the HLA-B51 major histocompatibility complex antigen ${ }^{4}$. Indeed, the global distribution of the HLA-B51 antigen in healthy individuals corresponds to the overall distribution of Behçet disease ${ }^{13}$. In this study, just over half of the patients who were tested carried the HLA-B51 antigen, with no difference between the NSR and SR populations. Studies in the literature reported similar rates of expression of HLA-B51 antigen in Behçet uveitis with consistency across populations from NSR and SR countries $14,15,16,17,18$.

Overall, the two patient populations showed similar demographic features. In both subgroups, the majority of patients was male and had bilateral disease. The average age at presentation was in the mid-thirties. These demographic characteristics were consistent with those from other reports of patients with Behçet uveitis 17,18,19,20,21,22. 
The ocular presentation of patients with Behçet uveitis was similar between the two subgroups of patients. In studies from different parts of the world, panuveitis was reported as the most frequent ocular manifestation in patients with Behçet uveitis'17, 20, 23, 24. In our patients, the commonest manifestation was retinal vasculitis associated with anterior uveitis and then panuveitis. One fifth of our patients manifested hypopyon formation at some point in their follow up. Similarly in the literature, a hypopyon was reported in 10$25 \%$ of patients $25,26,27$.

There was no significant difference between the two subgroups in the pattern of presentation of Behçet disease. Almost all patients were diagnosed with Behçet disease as part of their uveitis evaluation. The majority of patients first presented with systemic manifestations, most commonly oral or genital ulcers, before their eye disease developed, on average, 30 months later. Only 3 patients had uveitis as their onset manifestation of Behçet disease, and therefore performing a complete review of systems in all patients with uveitis will allow for the correct diagnosis in the majority of cases. Interestingly, 6 patients, all of NSR origin, had met the criteria for Behçet disease before onset of uveitis, but had not been given the correct diagnosis. No patients of SR ancestry met the criteria but were not given a diagnosis. This highlights the need to consider Behçet disease in all patients, regardless of racial/ethnic origins.

The most common ocular complication observed was cataract, followed by CME and ERM. All ocular complications occurred at similar rates in NSR and SR patients except for ERM which affected more SR than NSR patients. Results regarding ocular complications in our patients were similar to those in many other studies ${ }^{20,23,28}$. 
Apart from epiretinal membrane which occurred more frequently in SR patients $(\mathrm{p}=0.02)$, all other statistical comparisons between SR and NSR patients in clinical features produced insignificant p-values, highlighting the similarity between the two subgroups (Table 1, 2, and 3).

We reported a favorable clinical response and side effect profile in our patients who received a short-term, high-dose chlorambucil regimen and in those who received biologic agents. The number of patients was too small to draw conclusions. However, when patients from NSR and SR origins were compared, no difference in response to treatment was noted.

To the best of our knowledge, this is the first case series comparing the presentation and course of Behçet uveitis in patients of Silk Road versus non-Silk Road origins. Our number of patients was modest, as Behçet uveitis is uncommon in the United States. Therefore, conclusions regarding the demographics and response to therapy can only be drawn with caution. In particular, adequate assessment of the response to specific therapies merits randomized clinical trials to more reliably interpret results. However, until more accurate diagnostic testing is available for Behçet disease, these clinical studies are necessary to allow for prompt diagnosis and treatment of this potentially blinding disease.

In summary, we describe a cohort of 36 patients with Behçet uveitis from a tertiary referral center in the American Midwest. Although the percentage of patients of Silk Road descent was proportionally high compared to the overall uveitis population, greater than two thirds of patients were not of Silk Road origins. Clinically, patients from both the Silk Road and non-Silk Road subgroups had similar presentation. The most common ophthalmologic finding was retinal vasculitis in both groups. No difference was noted 
between groups in results of HLA-B51 testing, systemic manifestations, or response to treatment. While Behçet disease is more common in patients from Silk Road countries, physicians should be aware of the possibility of Behçet disease in all uveitis patients, particularly those with retinal vasculitis, regardless of country of origin. A complete review of systems is warranted, including assessment for oral and genital ulcers, as the systemic findings often precede the ocular findings and can provide clinical support for the diagnosis.

\section{Declaration of interest}

The authors have no financial or personal relationships with any person or organization that may result in conflict of interest. The authors alone are responsible for the content and writing of the paper.

Debra A Goldstein, MD, had full access to all the data in the study and takes responsibility for the integrity of the data and the accuracy of the data analysis. 


\section{Acknowledgments}

The authors wish to thank Sarju Patel, MD, for his help with the statistical analysis. 
Ocular manifestations in patients with Behçet uveitis

\begin{tabular}{|l|l|l|l|l|} 
Ocular findings & \multicolumn{1}{l}{ All patients } & SR & NSR & p value (SR \\
\multicolumn{2}{|c|}{$\mathrm{n}=36$} & \multicolumn{2}{c}{$\mathrm{n}=10$} & \multicolumn{2}{c|}{$\mathrm{N}=26$} & \multicolumn{2}{l|}{ vs NSR) } \\
\hline Retinal vasculitis & $31(86 \%)$ & $9(90 \%)$ & $22(85 \%)$ & $>0.99$ \\
\hline Panuveitis & $27(75 \%)$ & $7(70 \%)$ & $20(77 \%)$ & 0.69 \\
\hline Retinitis & $12(33 \%)$ & $4(40 \%)$ & $8(31 \%)$ & 0.70 \\
\hline Hypopyon & $8(22 \%)$ & $1(10 \%)$ & $7(27 \%)$ & 0.40 \\
\hline Anterior uveitis & $5(14 \%)$ & $1(10 \%)$ & $4(15 \%)$ & $>0.99$ \\
\hline Intermediate uveitis & $3(8 \%)$ & $1(10 \%)$ & $2(8 \%)$ & $>0.99$ \\
\hline Scleritis/sclerokeratitis & $2(6 \%)$ & $0(0 \%)$ & $2(8 \%)$ & $>0.99$ \\
\hline
\end{tabular}

Table1. Ocular features in patients with Behçet uveitis are shown for all patients. A comparison of SR and NSR patients shows that the ocular findings were similar in the two patient populations. 


\section{Systemic manifestations in patients with Behçet uveitis}

\begin{tabular}{|c|c|c|c|c|}
\hline $\begin{array}{l}\text { Systemic findings at } \\
\text { presentation }\end{array}$ & $\begin{array}{l}\text { All } \\
\text { patients } \\
\mathrm{N}=36\end{array}$ & $\begin{array}{l}\mathrm{SR} \\
\mathrm{n}=10\end{array}$ & $\begin{array}{l}\text { NSR } \\
n=26\end{array}$ & p-value \\
\hline Oral ulcers & $36(100 \%)$ & $10(100 \%)$ & $26(100 \%)$ & $>0.99$ \\
\hline Genital ulcers & $26(72 \%)$ & $7(70 \%)$ & $19(73 \%)$ & $>0.99$ \\
\hline Skin manifestations & $18(50 \%)$ & $7(70 \%)$ & $11(42 \%)$ & 0.26 \\
\hline - acneiform rash & $11(31 \%)$ & $5(50 \%)$ & $6(23 \%)$ & 0.22 \\
\hline - erythema nodosum & $4(11 \%)$ & $2(20 \%)$ & $2(8 \%)$ & 0.30 \\
\hline $\begin{array}{ll} & \text { superficial } \\
& \text { thrombophlebitis }\end{array}$ & $3(8 \%)$ & $0(0 \%)$ & $3(12 \%)$ & 0.54 \\
\hline Arthropathy & $11(31 \%)$ & $4(40 \%)$ & $7(27 \%)$ & 0.45 \\
\hline Fever/chills/night sweats & $4(11 \%)$ & $1(10 \%)$ & $3(12 \%)$ & $>0.99$ \\
\hline Neurological & $3(8 \%)$ & $1(10 \%)$ & $2(8 \%)$ & $>0.99$ \\
\hline Gastrointestinal & $2(6 \%)$ & $1(10 \%)$ & $1(4 \%)$ & 0.48 \\
\hline
\end{tabular}

Table2. Systemic findings in patients with Behçet uveitis. The most common findings, in addition to oral ulcers, were genital ulcers and skin manifestations of the disease. 


\section{Ocular complications in patients with Behçet uveitis}

\begin{tabular}{|c|c|c|c|c|}
\hline Ocular complication & $\begin{array}{l}\text { All patients } \\
\mathrm{N}=36\end{array}$ & $\begin{array}{l}S R \\
N=10\end{array}$ & $\begin{array}{l}\text { NSR } \\
N=26\end{array}$ & p-value \\
\hline Cataract & $15(42 \%)$ & $4(40 \%)$ & $11(42 \%)$ & $>0.99$ \\
\hline CME & $13(36 \%)$ & $3(30 \%)$ & $10(38 \%)$ & 0.72 \\
\hline ERM & $13(36 \%)$ & $7(70 \%)$ & $6(23 \%)$ & 0.02 \\
\hline $\mathrm{IOP} \geq 10 \mathrm{mmHg}$ above baseline & $6(17 \%)$ & $2(20 \%)$ & $4(15 \%)$ & $>0.99$ \\
\hline $\mathrm{VH}$ & $4(11 \%)$ & $0(0 \%)$ & $4(15 \%)$ & 0.56 \\
\hline Optic disc atrophy & $4(11 \%)$ & $1(10 \%)$ & $3(12 \%)$ & $>0.99$ \\
\hline Fundus neovascularization & $3(8 \%)$ & $0(0 \%)$ & $3(12 \%)$ & 0.54 \\
\hline Macular scar & $3(8 \%)$ & $2(20 \%)$ & $1(4 \%)$ & 0.18 \\
\hline Glaucoma & $2(6 \%)$ & $0(0 \%)$ & $2(8 \%)$ & $>0.99$ \\
\hline BRVO & $2(6 \%)$ & $0(0 \%)$ & $2(8 \%)$ & $>0.99$ \\
\hline BRAO & $1(3 \%)$ & $0(0 \%)$ & $1(4 \%)$ & $>0.99$ \\
\hline
\end{tabular}

Table3. Ocular complications diagnosed at any time point in patients with Behçet uveitis.

Epiretinal membrane (ERM) was more common in patients of Silk Road descent; otherwise, the two groups had similar complication rates.

ERM: Epiretinal membrane, CME: cystoid macular edema, IOP: intraocular pressure, BRVO: branch retinal vein occlusion, BRAO: branch retinal artery occlusion, OHTN: ocular hypertension, VH: vitreous hemorrhage. 
Biologic agents for patients with Behçet uveitis

\begin{tabular}{|c|c|c|c|c|c|}
\hline Patient \# & P1 & P2 & P3 & P4 & P5 \\
\hline $\begin{array}{l}\text { Biologic agent } \\
\text { used }\end{array}$ & IFX & IFX & ADB & ADB & ADB then IFX \\
\hline $\begin{array}{l}\text { Duration of Rx } \\
\text { (months) }\end{array}$ & 24 & 24 & 12 & 12 & $\begin{array}{l}6 \text { for ADB, } 5 \text { for } \\
\text { IFX }\end{array}$ \\
\hline $\begin{array}{l}\text { Number of attacks } \\
\text { per year before } \\
\text { starting Rx }\end{array}$ & 2.4 & 2 & 2.4 & 1.8 & 1.7 \\
\hline $\begin{array}{l}\text { Number of attacks } \\
\text { per year after } \\
\text { starting Rx }\end{array}$ & 0.9 & 0 & 0 & 0 & 0.3 \\
\hline $\begin{array}{l}\text { Prior systemic } \\
\text { therapies }\end{array}$ & $\begin{array}{l}\text { PRED, } \\
\text { CSA }\end{array}$ & $\begin{array}{l}\text { PRED, } \\
\text { CSA }\end{array}$ & $\begin{array}{l}\text { PRED, } \\
\text { CSA }\end{array}$ & $\begin{array}{l}\text { PRED, } \\
\text { MTX, AZT }\end{array}$ & PRED, MTX, CSA \\
\hline Adverse effects & None & None & None & None & $\begin{array}{l}\text { Frequent URTIs } \\
\text { with ADB, None } \\
\text { with IFX }\end{array}$ \\
\hline
\end{tabular}

Table4. Biologic agents for Behçet uveitis. Two patients were still on biologic therapy at the time of data collection.

P1 to P5: Patient's number, IFX: Infliximab, ADB: adalimumab, PRED: prednisone, CSA:

cyclosporine, AZT: azathioprine, MTX: methotrexate, URTI: upper respiratory tract infection. 


\section{REFERENCES}

1. Behçet H. Überrezidivierende aphthöse durch ein Virus verursachte Geschwüre am Mund, am Auge und an den Genitalien. DermatolWochenschr. 1937;105:1152-1157. 2. Michelson JB, Chisari FV. Behçet's Disease. SurvOphthalmol. 1982;26(4):190-203.

3. Elisseeff, V. Approaches Old and New to the Silk Roads. The Silk Roads: Highways of Culture and Commerce. Paris, UNESCO Publishing 1998. Reprint: Berghahn Books 2009. pp. 1-2. ISBN 978-92-3-103652-1.

4. Ohno S, Ohguchi M, Hirose S, et al. Close association of HLA-Bw51 with Behçet's disease. Arch Ophthalmol. 1982;100(9):1455-1458.

5. Behçet's Disease Research Committee of Japan. Behçet's disease: guide to diagnosis of Behçet's disease. Jpn J Ophthalmol. 1974;18:291-294.

6. International Study Group for Behçet's disease. Criteria for diagnosis of Behçet's Disease. Lancet. 1990;335(8697):1078-1080.

7. Kural-Seyahi E, Fresko I, Seyahi N, et al. The long-term mortality and morbidity of Behçet syndrome: a 2-decade outcome survey of 387 patients followed at a dedicated center. Medicine, 2003;82(1):60-76.

8. Yazici H, Fresko I, Yurdakul S. Behçet's syndrome: disease manifestations, management, and advances in treatment. Nat ClinPractRheumatol. 2007;3(3):148-155.

9. Gül A. Behçet's disease as an autoinflammatory disorder. Curr Drug Targets Inflamm Allergy. 2005;4(1):81-83. 
10. Jabs DA, Nussenblatt RB, Rosenbaum JT; Standardization of Uveitis Nomenclature (SUN) Working Group. Standardization of uveitis nomenclature for reporting clinical data: Results of the First International Workshop. Am J Ophthalmol. 2005;140(3):509-516. 11. Goldstein DA, Fontanilla FA, Kaul S, et al. Long-term follow-up of patients treated with short-term high-dose chlorambucil for sight-threatening ocular inflammation. Ophthalmology. 2002;109(2):370-377.

12. James DG. Behçet's disease. QJM. 2010;103(3):205.

13. Verity DH, Marr JE, Ohno S, et al. Behçet's disease, the Silk Road and HLA-B51: historical and geographical perspectives. Tissue Antigens. 1999;54(3):213-220. 14. Kitaichi N, Miyazaki A, Iwata D, et al. Ocular features of Behcet's disease: an international collaborative study. Br J Ophthalmol. 2007;91(12):1579-1582. 15. De Menthon M, Lavalley MP, Maldini C, et al. HLA-B51/B5 and the risk of Behçet's disease: a systematic review and meta-analysis of case-control genetic association studies. Arthritis Rheum. 2009;61(10):1287-1296.

16. Baricordi OR, Sensi A, Pivetti-Pezzi P, et al. Behçet's disease associated with HLA-B51 and DRw52 antigens in Italians. Hum Immunol. 1986;17(3):297-301.

17. Chung YM, Lin YC, Tsai CC, et al. Behçet's disease with uveitis in Taiwan. J Chin Med Assoc. 2008;71(10):509-516.

18. Ambresin A, Tran T, Spertini F, et al. Behçet's disease in Western Switzerland: epidemiology and analysis of ocular involvement. OculImmunolInflamm. 2002;10(1):5363.

19. Tugal-Tutkun I, Onal S, Altan-Yaycioglu R, et al. Uveitis in Behçet disease: an analysis of 880 patients Am J Ophthalmol. 2004;138(3):373-380. 
20. Khairallah M, Attia S, Yahia SB, et al. Pattern of uveitis in Behçet's disease in a referral center in Tunisia, North Africa. IntOphthalmol. 2009;29(3):135-141.

21. Alpsoy E, Donmez L, Onder M, et al. Clinical features and natural course of Behçet's disease in 661 cases: a multicentre study. Br J Dermatol. 2007;157(5):901-906.

22. Krause L, Köhler AK, Altenburg A, et al. Ocular involvement in Adamantiades-Behçet's disease in Berlin, Germany. Graefes Arch ClinExp0phthalmol. 2009:247(5):661-666. 23. Yang P, Fang W, Meng Q, et al. Clinical features of chinese patients with Behçet's disease. Ophthalmology. 2008;115(2):312-318.

24. Sáenz-Francés F, Elías-de-Tejada M, Martínez-de-la-Casa JM, et al. Ocular inflammatory signs observed in a cohort of Spanish patients with Behçet disease and ocular inflammation. Eur J Ophthalmol. 2008;18(4):563-566.

25. Barra C, Belfort Júnior R, Abreu MT, et al. Behçets disease in Brazil—a review of 49 cases with emphasis on ophthalmic manifestations. Jpn J Ophthalmol. 1991;35(3):339-346. 26. Benezra D, Cohen E. Treatment and visual prognosis in Behçets disease. Br J Ophthalmol. 1986;70(8):589-592.

27. Mishima S, Masuda K, Izawa Y, et al. The eighth Frederick H Verhoeff Lecture. Behçet's disease in Japan: ophthalmologic aspects. Trans Am Ophthalmol Soc. 1979;77:225-279. 28. Sungur G, Hazirolan D, Hekimoglu E, et al. Late-onset Behçet's disease: demographic, clinical, and ocular features. Graefes Arch ClinExpOphthalmol 2010;248(9):1325-1330. 